\title{
Claim Calculation of Multi-event Delay in International Project
}

\author{
Peng Zhang ${ }^{1, a}$, Quan-Chen Gao ${ }^{1, b}$, Shu-Liang $\mathrm{Gao}^{2, \mathrm{c}}$, \\ Zhen-Li Hao ${ }^{1,3, \mathrm{~d}^{*}}$, Yan-Ping Jiao ${ }^{1,3, \mathrm{e}}$ \\ ${ }^{1}$ School of Mechanics and Civil Engineering, China University of Mining and Technology (Beijing) \\ Beijing 100083, China \\ ${ }^{2}$ China Beijing Metallurgical Engineering Technology co., LTD, Beijing 100088, China \\ ${ }^{3}$ State Key Laboratory for GeoMechanics and Deep Underground Engineering Beijing, Beijing \\ 10083, China \\ a13671183969@163.com, b33251816@qq.com, 'zhongyeganggou@163.com, \\ dkanhai20007@163.com, ${ }^{\mathrm{e}} \mathrm{jia0y}$ anping1992@163.com \\ ${ }^{*}$ Corresponding author
}

Keywords: Construction delay, Construction clams, Multi-event delay.

\begin{abstract}
This paper defines the concept of construction time claim, and puts forward to analyze the claim procedure and claim processingmethod.Thepaper has carried on the quantitative analysis of multi-event delay, put forward the concept of effective claim time in the multi-events claim, then put forward the calculation method of construction claim and calculation steps.And it set up new parameters for the effective claim time, analyze the claim case, delimit claim responsibility and determine the claim values, finally propose the construction claim calculation based on the process delay of multi-event.
\end{abstract}

\section{Introduction}

There aregeneral not only the long construction periods and complicated construction technology in the international projects, but also during the construction, it will be the interference of external factors, which makes the project hardly according to the plan to finish and results in delays.Nowadays engineering project management software is often used to control the progress of the projects, but there are drawbacks that noeffective analyzeconstruction period delay. In terms of the main contractor, to apply for construction time claim, It not only determine whether the project goes as planned, but also make an analysis the condition of specific processesdelays and the cause of delay, and then according to the actual situation to calculate the number of days duration of the claim [1].For construction delays claim, the author make this study.

\section{Construction claim}

The construction time claim refers tothe project asnon-contractor's own reasons resulting in the construction period delay, the contractor towardthe owner apply for the extension of time limit. The contractors for construction time claimcan avoid the extension of constructiontimeto pay liquidated damages, as well as obtain their owncorresponding economic compensation.

\section{Analysis of construction delays claim}

After generating the construction delay, the contractor claims, according to the following steps:

Firstly, Analysis of thematter of construction time delays and finding out the reasons, if it is not caused by the contractor,the writer can further study whether make the construction claim;

Secondly, the delay eventsshould be analyzed and determined its impact on the network planning.If the delay occurs on the key lines, it will affect the total time limit of project and can make a claim for the delay of time limit for project.Normally, it will only consider the impact onthe total construction time of the process in the analysis of construction claim. However, becausethe 
project is in the dynamic changes and the impact on the totalconstruction time of the process is also dynamic change, therefore, the network planning must be adjusted in accordance with the latest schedule to determinein determining the key working procedure.

Finally, after determining the construction time claim, whether to produce cost claim should also be analyzed.If the reason of ownerswillresult in the construction costof contractor increasing, it also can undertake the costclaims.If it is not caused by the owners, the construction time claim can be apply.

\section{Analysis of construction delay claims processing methods}

According to the impact of betweenclaims events divided,it can usually be divided into two kinds of categories:singleevent delays claim and multi-eventsdelays claim.Generally speaking, singleevent delay claims, according to the causes of the incident and the impact of processing, isrelatively simpleand easy to divide responsibilities, measurement easier and the two sides rarely produce controversy.

First, the events delay responsibility and attribution of responsibility is difficult to distinguish and define in the interaction of events;

Second, if the multi-events work together to form a common delay, there must be differences between delay loss quantification and share in the responsible party;

Third, the interaction between processeshave an impact on the key linescaused the total time of uncertainty, and the follow-up process will take place in change on the network diagrams, which make the construction period delayis very hard to measure andtruly determine the construction period delay loss. It is difficult to reflect the real situation of the construction period clam and cost clam for the contractor;

For multi-events delayed, due to the contracting partiesmay beunderstanding the problem, such as the definition of responsibility for the delay, especially how to quantifyboth sideshave controversialand great differences.In addition, there is also a great dispute for responsibility for quantifying, by which side assumed and performed responsibility, whether it would be fair, which make the two sides hardly reach an agreement in the dispute, so that the claim was unsustainable. Thus, for multi-event delay in the processing of claims, how to scientifically and reasonably quantified and shared responsibility has become a top priority of the success of the claim.

\section{Calculation methods of multi-events construction delay claim}

The calculation methods ofconstructionclaim is proposed under multi-eventstime delay in this section, namely the new parameters will be introduced into the network plan figure and took into account the two factors that the process itself delayand the starting time delayat the same time. The variables of processdelay were analyzed, and finding out the real problem of project delays, thusthe calculating model of construction claim can be established, which provide the quantitative of method for contractor at the construction claims divided responsibility.

This method will collect and analyzethe date to obtain the reasons for the processdelay, set up corresponding variables and the influence on the total time limit ofvariables, determine the effective delay process, and then combine with the actual situation analysis and find outthe effective delay process of the reasons for the delay, and againdivide delay responsibility, according to the claim calculation model to calculate the value of the time claim that can be made.As shown in figure 1.

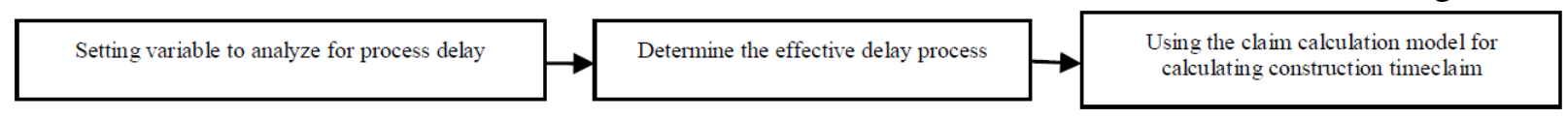

Fig.1 Calculation steps of duration claims

\section{Set up the new time parameter}

Each working procedure has six time parameters in the network plan. But in the process of construction, the actual construction progress is differences with the original plan. By comparing 
with the original time parameters change, it is true to reflect the actual process delays existing differences. In this paper, the new time parameter variables will be introduced:11process actual starting time (AS), (2) process actual finishing time (AF), (3) process plan starting time (PS), (4) process plan finishing time (PF), (5)process the actual duration time (AD), 6) process plan duration time (PD)), (7) process can starting time (CS).

The time parameter is the following relation in the process of $\mathrm{i}-\mathrm{j}$ :

$$
\begin{aligned}
& \mathrm{AF}_{i-j}=\mathrm{AS}_{i-j}+\mathrm{AD}_{i-j} . \\
& \mathrm{PF}_{i-j}=\mathrm{PS}_{i-j}+\mathrm{PD}_{i-j} . \\
& \mathrm{CS}_{i-j}=\max \left\{\mathrm{AF}_{h-j}\right\}, h<i<j .
\end{aligned}
$$

\section{The determination of effective delay process}

When the work procedure of delay time is more than the total float time, it will affect the total time limit for project.To study the process delay timehave effects onthe total time, and setting variable PA represents the differencebetween the process delay time and thetotal float time. If the value of PA is larger, it shows the process time delaylonger, givesmore impact on total time. The formula such as (4):

$$
\mathrm{PA}_{i-j}=\mathrm{VA}_{i-j}-\mathrm{TF}_{i-j}
$$

\begin{tabular}{|c|c|c|}
\hline \multicolumn{2}{|c|}{ Variable } & The analysis of effect \\
\hline \multicolumn{2}{|r|}{$\mathrm{PA} \leq 0$} & $\begin{array}{l}\text { If the process delay is in the scope of total float time, the process delay will } \\
\text { not affect the project time. If } \mathrm{VA}_{i-j} \leq 0 \text {, because there is no possibility the } \\
\text { negative value for } \mathrm{VSS}_{i-j} \text {, so the } \operatorname{VD}_{i-j} \text { should be negative, that is, the process } \\
\text { is to accelerate the construction. }\end{array}$ \\
\hline \multirow[t]{2}{*}{$\mathrm{PA}>0$} & $\begin{array}{l}\text { If the process is the } \\
\text { key work in the } \\
\text { original network plan, } \\
\text { the total float time is } \\
\text { equal to } 0\end{array}$ & $\begin{array}{l}\text { The process have no available to the free float time, the delay will directly } \\
\text { affect the delay of the total t time. } \\
\text { (1) If the process is still the key work after the affected network plan, } \\
\mathrm{PA}_{i-j}=\mathrm{VA}_{i-j} \text {; (2) If the process transform into the non-critical work after the } \\
\text { affected network plan, the } \mathrm{PA}_{i-j} \text { is uncertain, the analysis should be carried as } \\
\text { the practical situation. }\end{array}$ \\
\hline & $\begin{array}{l}\text { If process is the } \\
\text { non-critical work in the } \\
\text { original network plan }\end{array}$ & $\begin{array}{l}\text { (1) } \mathrm{VA}_{i-j}<\mathrm{TF}_{i-j} \text {, the process delay has no effect on total duration, } \mathrm{PA}_{i-j}=0 \text {; } \\
\text { (2) } \mathrm{VA}_{i-j}>\mathrm{TF}_{i-j} \text {, } \text {, ke key line have been changed, it combined with the actual } \\
\text { situation to calculate claim time; (3) } \mathrm{VA}_{i-j}=\mathrm{TF}_{i-j} \text {, the process delay has no effect } \\
\text { on the total duration, but it may change the key lines. }\end{array}$ \\
\hline
\end{tabular}

Tab.1 The analysis of process delay effect on total duration

\section{The Calculation of multiple event time claim process based delay}

From the above content that can be seen, process delay does not necessarily affect the total time limit for a project, but the affected total duration must be caused by the accumulation of a lot of delay process. Therefore, it is required to analyze process to determine the responsible parties and responsibility division of the total time delay. Firstly, according to the actual situation, collects process delay information and determines the effective delay process; Secondly, analyzes the reasons and analyzes the responsibility reasons carried out in accordance with for three aspectsof owners, contractors, and the force majeure; Then, adjust the network diagram which is based on the construction site files and records, set up calculation model for calculating claim time limit value.

The key line often can change after network planning is disturbed which causing project delay value small that delays is a unilateral factors affecting the action of the time limit and there is a difference between delta with the time delay value under the influence of the three factors, which 
the $T_{o}, T_{c}, T_{f}$ is respectively for owners, contractors, and the force majeure factors caused by unilateral project delay value, $\mathrm{T}_{\text {ocf }}$ is standing for project delay of three factors combing action.

$$
T_{o c f}=T_{o}+\mathrm{T}_{c}+T_{f}+\Delta
$$

Tab.2 The numerical analysis of $\Delta$

\begin{tabular}{|c|c|}
\hline Difference between delta values & Situation analysis \\
\hline Positive values & $\begin{array}{c}\text { Time limit for a project under the action of extension is greater than the time } \\
\text { limit for a project under the action of separately extension value, the time use } \\
\text { is not ideal when working together. }\end{array}$ \\
\hline Negative values & $\begin{array}{r}\text { The time delay of reasons for owners, contractors, and the action of force } \\
\text { majeure is less than the value of the time delay sum separately under the } \\
\text { action and the interaction time is more ideal. }\end{array}$ \\
\hline Value is zero & $\begin{array}{r}\text { The delay time of every factor can be directly compared and added together, } \\
\text { when the key circuit of network plan is without a shift. }\end{array}$ \\
\hline
\end{tabular}

To analyze the effect of various factors on the difference of the delta coefficient $\mathrm{K}_{\mathrm{O}}, \mathrm{K}_{\mathrm{C}}, \mathrm{K}_{\mathrm{F}}$ to represent the influence degree of owners, contractors, and the force majeure to the delta, then:

$$
\begin{aligned}
& \mathrm{K}_{o}=\frac{\mathrm{T}_{o}}{\mathrm{~T}_{o}+\mathrm{T}_{c}+\mathrm{T}_{f}} . \\
& \mathrm{K}_{C}=\frac{\mathrm{T}_{c}}{\mathrm{~T}_{o}+\mathrm{T}_{c}+\mathrm{T}_{f}} . \\
& \mathrm{K}_{\mathrm{F}}=\frac{\mathrm{T}_{f}}{\mathrm{~T}_{o}+\mathrm{T}_{c}+\mathrm{T}_{f}} . \\
& \Delta=\mathrm{K}_{o} \Delta+\mathrm{K}_{C} \Delta+\mathrm{K}_{\mathrm{F}} \Delta .
\end{aligned}
$$

The conclusion:

The substitution of Eq. (9) into Eq. (5) results in the following equation:

$$
\mathrm{T}_{\mathrm{OCF}}=\left(\mathrm{T}_{\mathrm{O}}+\mathrm{K}_{\mathrm{O}} \Delta\right)+\left(\mathrm{T}_{\mathrm{C}}+\mathrm{K}_{\mathrm{C}} \Delta\right)+\left(\mathrm{T}_{\mathrm{F}}+\mathrm{K}_{\mathrm{F}} \Delta\right)
$$

To sum up, in multi-event delay case, the total construction period delay TOCF consists of three parts delay: the owner delay value $\mathrm{TO}+\mathrm{Ko} \Delta$, the contractor delay value $\mathrm{TC}+\mathrm{Kc} \Delta$, and force majeure delay value $\mathrm{Tf}+\mathrm{KF} \Delta$.

To the delay of three factors as follows:

Delays caused by owner factors $\mathrm{TO}+\mathrm{Ko} \Delta$ can be claimed and can be compensated. That is, the contractor can make a claim to the owners of the construction period and it can also make a claim to the owners expense to make up for their economic losses.

Delays caused by force majeure $\mathrm{TF}+\mathrm{KF} \Delta$ can be claimed and cannot be compensated, that is, the contractor can only claim for construction.

Time delaycaused by the contractor $\mathrm{TC}+\mathrm{Kc} \Delta$ itself belongs to delay that cannot be claimed, that is, the contractor can oneself bear the loss that caused by delays.

In summary, in the case of multi-event delay, the contractor to the ownersfor time claim, that is the valid claim duration should be as follows:

$$
\mathrm{TC}=\left(\mathrm{T}_{O}+\mathrm{K}_{O} \Delta\right)+\left(\mathrm{T}_{F}+\mathrm{K}_{F} \Delta\right)
$$




\section{References}

[1] Lv Shengpu. The research on time limits for a project and cost under the conditions of FIDIC contract, D. Tianjin University of Technology, 2006.

[2] Li Qingxun, The Composition and Calculation of the Claim on International Engineering Project Construction Period Delay Cost, J. Project Management Techniques, 2009 (11): 61-63.

[3] Chen yu. The Claims Analysis on International Engineering and Its Application in the Xiao Lang Di Project, D. Hehai University, 2006.

[4] Yang Dexin. The Research on Multi-event interference delays claim principle, J. Civil Engineering Journal, 2003, 36(3):37-45.

[5] Qiao Baihe. The Research on Project Claim Management and Time Limit for a Project Delay Claim, D. Chang`an University, 2006. 